\title{
Analysis of Daily Body Weight of High-Producing Dairy Cows in the First One Hundred Twenty Days of Lactation and Associations with Ovarian Inactivity
}

\author{
M. van Straten, ${ }^{\star}+\ddagger^{1}$ N. Y. Shpigel, $\dagger$ and M. Friger $¥$ \\ ${ }^{*}$ Hachaklait, Mutual Society for Veterinary Services, POB 3039, Caesarea Industrial Park 38900, Israel \\ †Koret School of Veterinary Medicine, Faculty of Agriculture, Hebrew University of Jerusalem, POB 12, Rehovot 76100, Israel \\ ‡Department of Epidemiology and Health Service Evaluation, Faculty of Health Sciences, Ben-Gurion University of the Negev, POB 653, Beer \\ Sheva 84105 , Israel
}

\section{ABSTRACT}

The objective of this study was to investigate, describe, and quantify daily body weight (BW) changes in the first $120 \mathrm{~d}$ of lactation in high-producing dairy cows. Data included 255,287 daily BW measurements from 2,167 Israeli Holstein dairy cows originating from 7 commercial dairy farms. Individual series of measurements were first smoothed using cubic splines for generating variables representing $\mathrm{BW}$ changes in early lactation and further analysis of the data. To construct standard BW curves stratified by parity and adjusted for farm, mixed models for repeated measurements were fit to the smoothed data, and least squares means for day in lactation were plotted. Time-series analysis techniques using polynomial functions of day in lactation and pairs of sine and cosine functions representing 7- and 21-d cycles were performed separately on each individual series of measurements. Additionally, generalized estimating equations were used to perform similar analysis on the data set as a whole. Mean days from calving to nadir BW increased significantly from first to later parities, as did mean BW loss from calving to nadir. The first-parity cow lost $6.5 \%$ of her BW from calving to $\mathrm{d} 29$ in lactation, and second-parity and greater-parity cows lost 8.5 and $8.4 \%$ of their BW to d 34 and 38 in lactation, respectively. After nadir BW was reached, first-parity cows regained relative BW at a greater rate than did older parity cows. The trend in BW was nonlinear. A 7-d cycle was present in 247 cows (11.4\%) and a 21-d cycle was present in 715 cows (33.0\%). Presence of a 21-d cycle was associated with a $33 \%$ reduction in the risk of being diagnosed with inactive ovaries. Fewer days from calving to nadir BW and smaller BW loss from calving to nadir, coupled with a faster post-nadir increase in relative BW in first-parity

Received January 15, 2008.

Accepted May 20, 2008.

${ }^{1}$ Corresponding author: chkl351@netvision.net.il cows compared with older cows indicated a smaller energy deficit in early lactation. Association between 21-d cycles in BW and ovarian activity suggest that these cycles were physiological and related to the estrous cycle. Therefore, monitoring them could be useful for indirectly assessing ovarian activity in a herd.

Key words: body weight, dairy cow, time-series analysis

\section{INTRODUCTION}

Negative energy balance (NEB) is considered a physiological phenomenon in high-yielding dairy cows in early lactation (Goff and Horst, 1997). In this period, metabolic and endocrine changes allow enhanced mobilization of body fat and skeletal muscle breakdown and favor diversion of absorbed metabolites to the mammary gland to supply sufficient substrates for synthesis of milk. Because most cows undergo a state of NEB in early lactation and eventually recover from this state, Jorritsma et al. (2003) suggested the term "adaptation to NEB." They define cows as less adapted when certain risk factors such as a longer lasting or deeper calculated NEB (cNEB) or certain biochemical, endocrinological, or (sub)clinical characteristics are present. However, the degree of adaptation in the individual cow is difficult to determine and unsurprisingly, many risk factors have been investigated and proposed. Among these are cNEB (de Vries and Veerkamp, 2000; Reist et al., 2003a), BCS (Buckley et al., 2003; Roche et al., 2007), milk, blood, and urine metabolic parameters (Reist et al., 2002; LeBlanc et al., 2005), milk solids and their ratios (Reist et al., 2002) and, to a much lesser extent, BW changes (Marion et al., 2006; Roche et al., 2007). Assessing adaptation to NEB at the herd and cow level is important, as poor adaptation to NEB is detrimental to health status (Bobe et al., 2004), reproductive performance (de Vries et al., 1999; de Vries and Veerkamp, 2000; Reist et al., 2003a), and milk production (Reist et al., 2003b). It is important to distinguish 
between traits that are measured exclusively at the cow level and those that are not. An example of the latter is the commonly used cNEB. For calculating cNEB, general assumptions are made on energy requirements for maintenance and on milk production with a certain composition (Jorritsma et al., 2003). There is variability in feed efficiency between breeds, selection lines, or as expressed as heritability (Veerkamp, 1998). Calculated NEB does not capture individual variability, and differences in (feed) management and feed composition are not taken into account (Bruinenberg et al., 2002). It follows that it is not necessarily possible to apply cNEB to the individual cow for quantification of adaptation to NEB.

Daily BW is measured exclusively at the cow level and reflects what is happening in the individual cow. The frequency, objectivity, and small labor commitment associated with automated technology make daily BW an attractive tool to help measure the energy balance of individual cows, and the use of automated daily BW as a managerial tool has been suggested (Maltz, 1997; Maltz et al., 1997). Besides the more common use of BW for calculating energy balance, various studies found associations between BW and BW differences at key points in lactation and various reproductive measures. Buckley et al. (2003) used individual BW measured at 2.5- to 5-wk intervals and found that greater BW gain in the $90 \mathrm{~d}$ after the start of breeding was associated with greater rates of submission for breeding and greater rates of pregnancy to first service. Dechow et al. (2004) used daily BW measurements to study the effect of BW change $2 \mathrm{wk}$ before $\mathrm{AI}$ on the success of AI. Cows losing $>3.8 \mathrm{~kg}$ of BW in the 2 wk before AI were significantly less likely to conceive compared with those gaining $>7.7 \mathrm{~kg}$. Marion et al. (2006) investigated the relationship between BW change between calving and 30 DIM and the occurrence of disease. Cows losing more weight in this period were at a greater risk for displaced abomasum, ketosis, and metabolic disease.

Recently, comprehensive work evaluated the relationships between BW, BCS, and health-related and reproductive outcomes in pasture-based dairy cows. Berry et al. (2007a) found no relationship between periparturient BCS or BW and the incidence of dystocia or stillbirth. In another study (Berry et al., 2007b), significant relationships were found between BW (changes) in early lactation and SCS; however, these were not considered to be of biological significance. Roche et al. (2007) found significant relationships between reproductive performance and BW or BCS at key points, and BW and BCS change during lactation. Performance was negatively affected when BW and BCS measures indicated increased severity and duration of postpartum NEB.
To our knowledge, no comprehensive studies have been carried out to analyze and describe daily changes in BW in large numbers of high-producing dairy cows on commercial farms. Furthermore, knowledge of the dynamics of daily BW in high-producing dairy cows provides basic insight essential for management and optimal nutrition. Standard BW curves could be used for monitoring management and nutrition and for identifying production groups (e.g., second-parity cows) within a farm, suffering from maladaptation to NEB.

The aims of this study were to investigate, describe, and quantify daily BW changes in the first 120 DIM in high-producing dairy cows on commercial dairy farms. Furthermore, an attempt was made to construct standard BW curves for first-, second-, and older parity cows in the first 120 DIM.

\section{MATERIALS AND METHODS}

\section{Study Design and Population}

The study was designed as an observational, prospective cohort study and was conducted in a convenience sample of 7 typical Israeli commercial dairy farms from different geographical areas in Israel. The study population consisted of high-producing Israeli Holstein cows, held under zero grazing in free-stall sheds. All farms fed a TMR ad libitum. The farms used automated walk-through scales for the measurement of daily BW (S.A.E., Kibbutz Afikim, Israel) connected to the farm computer (Afifarm computerized milking and management software, Kibbutz Afikim, Israel) and were willing to participate in the study. Herd size ranged from 251 to 824 cows.

Farms included were members of the Israel Cattle Breeders Association (ICBA), performed monthly milk recordings, and participated in the Herd Health Program of "Hachaklait," the Mutual Society for Veterinary Services (Caesarea Industrial Park, Israel). Within this program, all cows were examined at 5 to $14 \mathrm{~d}$ postpartum for uterine disease. Sick cows and cows with a reduced milk production were checked for ketosis. These data, along with management, health, production, and reproduction data were recorded on the farm computer using either NOA (ICBA) or Afifarm management software.

During the months of March and June 2006, scales on all farms were calibrated. Scales were additionally calibrated approximately every 4 mo. For each farm, the study period started after initial calibration. Data collection ended by August 31, 2007. Details on geographical area, size, and milk production of the participating farms are in Table 1. 
Table 1. Size, average milk yield per cow, and geographical region of the participating farms (Herd Book Summaries, 2006, ICBA, Caesarea Industrial Park, Israel)

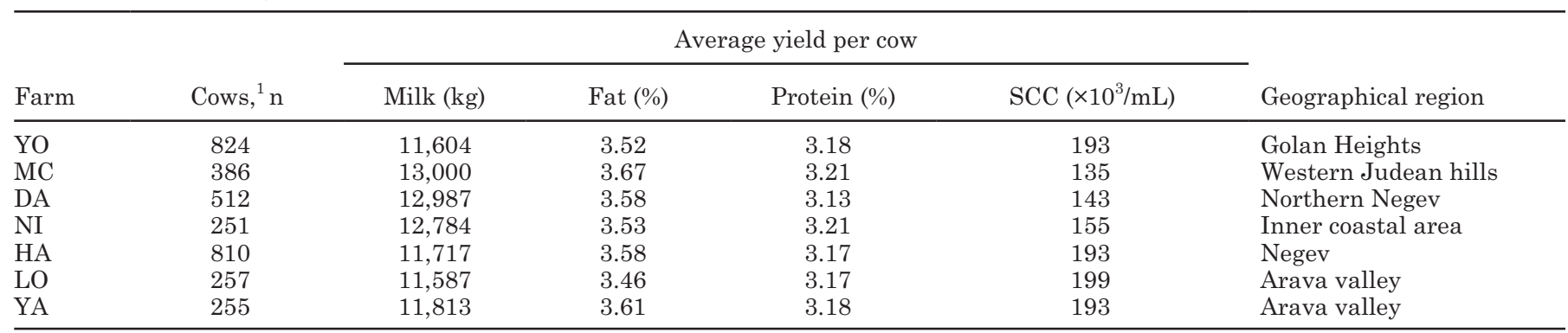

${ }^{1}$ Number of cows: annual average, including $\mathrm{n}$ cows.

\section{Data Editing and Statistical Analyses}

All data editing and analyses were performed using SAS version 9.1 (SAS Institute, 2006). Results were considered statistically significant if the $P$-value was $\leq 0.05$.

Calving, Management and Production Data. Data were retrieved from the farm computer (Afifarm or NOA management software). Definitions of the variables used are summarized in Table 2. Calving data included the variables milk fever, stillbirth, retained placenta, metritis, displaced abomasum, ketosis, unobserved estrus, and inactive ovaries. Body condition score (5-point scale) was assigned by the attending veterinarian at 3 fixed time points: calving ( 5 to $14 \mathrm{~d}$ after calving), 40 to 60 DIM, and at drying off (within 2 wk before date of drying-off in the previous lactation). Daily milk production $(\mathrm{kg})$ was available from d 1 to 90 in lactation.

Daily BW Data Editing. Cows were automatically weighed on their way back from the milking parlor 3 times daily. The 3 measurements were arithmetically averaged to 1 value for further analysis. If 1 or 2 of the 3 measurements were missing, the remaining measurements were used and treated as a daily measurement.
Cows participating had to have BW measurements from calving to 120 DIM. Each cow (a cow within a given lactation) was assigned a unique identification number constructed by its herd book number, farm number, and parity number. With the exception of time-series analysis, analyses were performed in 3 strata: first-parity cows, second-parity cows, and cows of parity 3 and greater, because of finding significant interactions between parity and day in lactation in BW change in models including parity as a fixed effect, to avoid the inclusion of interaction terms, and to obtain specific values for the different parity groups.

Data Smoothing. For generating variables representing BW changes in early lactation and further analysis of the BW data, individual measurements were first smoothed using cubic splines (Figure 1).

In this procedure, a nonparametric model was used using penalized least squares estimates for each subject. The model contained the time unit DIM as a single smoothing variable. The smoothed value for a given DIM was generated by minimizing the following quantity $(Q)$ :

$$
Q(\alpha)=\sum_{i=1}^{n}\left[y_{i}-\mu\left(t_{i}\right)\right]^{2}+\alpha \int_{-\infty}^{\infty}\left[\mu^{\prime \prime}(t)\right]^{2} \mathrm{~d} t
$$

Table 2. Definitions of variables used in the statistical analysis

\begin{tabular}{ll}
\hline Variable & Definition \\
\hline Milk fever & Periparturient recumbency, treated with calcium \\
Stillborn calf & Calf dead within $24 \mathrm{~h}$ of calving \\
Retained placenta & Placental membranes visible in vulva $24 \mathrm{~h}$ after calving \\
Metritis & $\begin{array}{l}\text { Abnormal vaginal discharge with or without systemic } \\
\text { disease at routine postpartum inspection }\end{array}$ \\
Displaced abomasum & Clinically diagnosed by the attending veterinarian \\
Ketosis & Urine acetoacetic acid concentration $\geq 1.5 \mathrm{mmol} / \mathrm{L}^{1}$ \\
Unobserved estrus & Cows presented to the attending veterinarian after the voluntary \\
Inactive ovaries & rest period with the complaint of not being observed in estrus \\
& Cows with "unobserved estrus" rectally examined twice by the \\
Summer calving & attending veterinarian (1-wk interval) with no corpus luteum \\
\hline
\end{tabular}

${ }^{1}$ Ketostix (Bayer, Dublin, Ireland). 


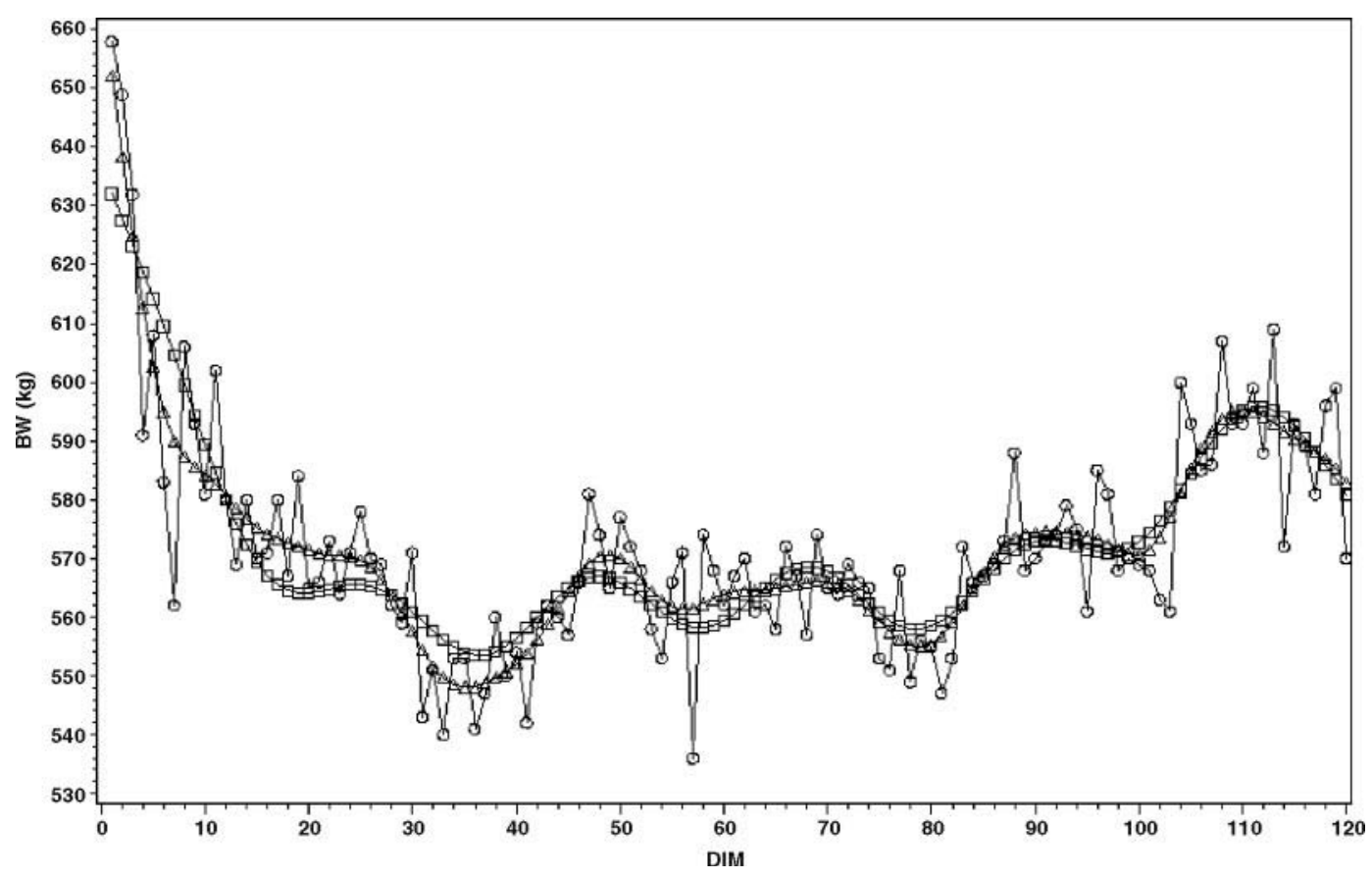

Figure 1. An example of raw data (०), polynomial smoothing ( $\square$ ), and cubic splines smoothing $(\Delta)$ of daily BW from calving to 120 DIM from 1 cow.

where $y_{i}$ is the observed BW at DIM $i, \mu\left(t_{i}\right)$ is a cubic function of DIM $I$, and a represents a trade-off between closeness of fit to the data, as measured by the residual sum of squares, and smoothness of $\mu(t)$, as measured by the integral term (Diggle, 1990).

As many unique design points as there were BW measurements were used for each time series and the trade-off between goodness of fit and smoothness (a) was determined by minimizing the generalized crossvalidation function (PROC TPSPLINE; SAS Institute, 2006).

(Relative) BW Changes and Standardized BW Curves. Relative BW change was calculated as

$$
\text { Relative BW change }=\frac{B W_{T}-B W_{C}}{B W_{C}},
$$

where $B W_{T}$ is smoothed BW at any given DIM, and $B W_{C}$ is $\mathrm{BW}$ at calving.

Differences in BW at calving, BW loss to nadir, and days to nadir BW across the different parities and farms were evaluated by ANOVA within the framework of a general linear model. This approach was preferred due to the unbalanced nature of the data. The general form of the models used for this analysis was:

$$
\begin{gathered}
\mathrm{Y}=\text { farm }(7 \text { index variables })+\text { parity } \\
\text { (3 index variables })+e,
\end{gathered}
$$

where $\mathrm{Y}$ is the mean of the value of interest (e.g., BW at calving), farm and parity the independent variables, and e the residual error. Significance of the source of variation was determined using the $F$-test for the type III sum of squares (PROC GLM; SAS Institute, 2006).

Data required to construct standard relative BW curves stratified by parity and adjusted for farm were obtained by fitting mixed models for repeated measurements to the smoothed data. Farm was included as a random effect and the model contained the time unit DIM as a single fixed effect. The following mixed model was used:

$$
\mathrm{Y}=\mathrm{DIM}(120 \text { index variables })+\text { farm }(\text { random })+\mathrm{e} ;
$$

where $\mathrm{Y}$ is the mean relative BW for a particular DIM, farm a dependent variable, and e a complex error term representing the within-cow correlation of BW measurements and the residual error. The covariance structure chosen for the $\boldsymbol{R}$ (error) matrix was autoregressive; that is, $\left(\sigma^{2} \rho^{|i-j|}\right)$.

Body weight curves were constructed by plotting the estimated least squares means of the fixed effect. Significance of the fixed effects was determined using the $F$-test (PROC MIXED; SAS Institute, 2006).

Time-Series Analysis. Initially, BW measurements were analyzed from each cow separately. For this purpose, a classical time-series technique was used: the 
time series were represented in an additive form as the sum of the trend component, periodic component, and "white noise" or random error component. The trend $\operatorname{Tr}\left(Y_{t}\right)$ of the time series was represented by polynomial functions of the time unit DIM up to the eighth order (i.e., polynomial smoothing) in the following form:

$$
\operatorname{Tr}(Y t)=a_{0}+a_{1} \cdot t+a_{2} t^{2}+a_{3} t^{3}+\cdots+a_{8} t^{8},
$$

where $t$ is DIM and $a_{i}(i=0,1, \ldots, 8)$ is the coefficient of the polynomial function.

The periodic component of the time series was represented by pairs of sine and cosine functions representing 7- and 21-d cycles, respectively. In the general form

$$
\sum_{i=1}^{k}\left[b_{i} \cos \left(\omega_{i} t\right)+c_{i} \sin \left(\omega_{i} t\right)\right]
$$

where $k$ is the number of considered cycles (in our case 2 ) and $t$ is DIM. Each pair of trigonometric functions represents 1 cycle; $\omega_{i}$ denotes the frequency of the periodic oscillations with a period of $T_{i}$ days $(i=1,2)$ :

$$
\omega_{i}=\frac{2 \pi}{T_{i}} .
$$

For the case $T_{1}=7$, the significance of a 7-d cycle was tested and for the case $T_{2}=21$, the significance of a 21-d cycle was tested.

The final polynomial-harmonic model had the following form:

$$
\begin{aligned}
Y t= & a_{0}+a_{1} \cdot t+a_{2} t^{2}+a_{3} t^{3}+\cdots+a_{8} t^{8} \\
& +\sum_{i=1}^{2}\left[b_{i} \cos \left(\omega_{i} t\right)+c_{i} \sin \left(\omega_{i} t\right)\right]+e_{t},
\end{aligned}
$$

where $e_{t}$ is the white noise.

The regression was performed using a stepwise selection method where variables with an $F$-statistic significant at 0.15 entered the model, but only those with an $F$-statistic significant at 0.05 stayed in the model. Additionally, the adjusted $\mathrm{R}^{2}$ value from each individual regression model was obtained.

A similar analysis was performed on the data set as a whole. The generalized estimating equations (GEE) model was used to adjust for repeated measurements of BW from the same cow. The model included the same polynomial functions and trigonometric functions used in the time-series analysis. The link function chosen was identity and the covariance structure used for the

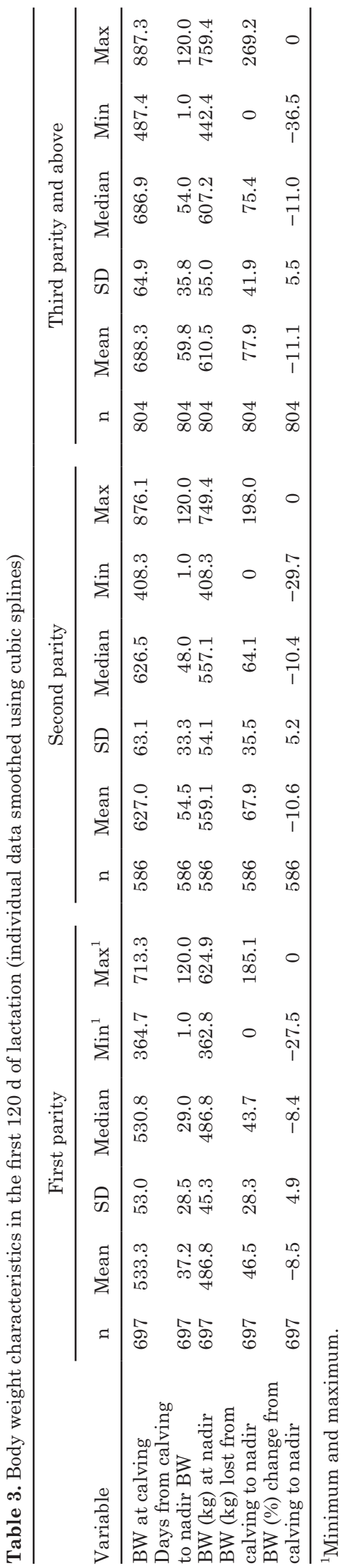

Journal of Dairy Science Vol. 91 No. 9, 2008 
working matrix $\mathbf{M}$ was autoregressive; that is, $\left(\sigma^{2} \rho^{|i-j|}\right)$. The level of significance associated with the independent variables was based on the GEE score statistic (PROC GENMOD; SAS Institute, 2006).

Relationship Between the Binary Variable Inactive Ovaries and Other Covariates. For this purpose, a multivariate logistic regression model was used. Before inclusion in the model, association between the dependent variable (inactive ovaries) and potential independent variables was tested using either the chisquare test for independence in the case of categorical variables, or the $t$-test for independent samples in the case of continuous variables. Independent variables significantly associated with the dependent variable were investigated for the presence of collinearity using the same tests. Finally, the significant independent variables (farm, summer calving, the presence of a 21-d cycle in BW and BCS at calving) were consecutively entered into the model using the Wald chi-square as a test for significance. Odds ratios were obtained by exponentiation of the regression coefficients of the model (PROC LOGISTIC; SAS Institute, 2006).

\section{RESULTS}

\section{(Relative) BW Changes and Standardized BW Curves}

Body weight measurements for the first 3 DIM were missing in 76 (3.5\%) cows and these cows were omitted from the analysis of BW changes. Characteristics of BW and BW changes are summarized in Table 3. Distribution of BW $(\mathrm{kg})$ at calving $(\mathrm{n}=2,091)$ approximated a normal distribution and differed significantly across parity (533.3, 627.4, and $690.7 \mathrm{~kg}$ for first, second, and older parity, respectively) and farm $(P<0.001)$.

The distribution of days from calving to nadir (DCN) was skewed to the right. Sixty-seven (3.3\%) of the cows were at a minimum BW at calving (i.e., BW nadir at d 1 postpartum). One hundred thirty cows (6.3\%) did not reach a nadir in BW within 120 DIM. For these cows, DCN was set at 120 . Mean DCN differed significantly across parity (37.2, 54.5, and $59.8 \mathrm{~d}$ for first, second, and older than second parity, respectively) and farm $(P<0.001)$. Mean loss of BW from calving to nadir BW $(\mathbf{L C N})$ differed significantly across parity and farm $(P$ $<0.001$ ). A positive LCN indicates a loss in BW. Mean LCN for the different parity groups were 46.5, 67.9, and $77.9 \mathrm{~kg}$ for first, second, and greater parities, respectively. The distribution of LCN was skewed to the right and approximated a normal distribution when transformed with the function (Diggle, 1990):

$$
L C N^{\prime}=\sqrt{(L C N+0.5)},
$$

where LCN' is the transformed value of LCN.

Relative change in BW (\%) from calving to nadir BW (RCN) differed significantly across parity $(-8.5,-10.6$, and -11.1 for first, second, and greater parities, respectively) and farm $(P<0.001)$. A negative RCN indicated a loss in BW.

Significant correlations were found among the various BW variables and BCS (Table 4). These did not differ across parity in direction (and only slightly in magnitude in some cases) and were therefore not stratified by parity. Body weight at calving showed significant correlations with BW at nadir (0.91), DCN (0.42), LCN $(0.60)$, and RCN (-0.42). On the other hand, BCS at 40 to 60 DIM was less correlated with LCN $(-0.20)$ and RCN (0.24), but had a greater correlation with BCS at calving (0.48). In general, cows calving with a greater BW had a greater nadir BW, but lost more BW for a longer time. Significant relationships between several BW traits, calving diseases, and milk production were found (data not shown).

Data for the construction of standard relative BW curves included 250,920 daily BW measurements. Standard relative BW curves corrected for the random effect of farm and the correlation between repeated measurements in the same cow are presented in Figure 2. For the standard cow, relative BW change in the first 15 DIM appears quite similar in all parities. Nadir BW was reached at d 29, 34, and 38 for parities 1, 2, and

Table 4. Correlations $(P)$ among BW and BCS variables

\begin{tabular}{|c|c|c|c|c|c|c|}
\hline & $\begin{array}{l}\text { Nadir } \\
\text { BW }\end{array}$ & $\begin{array}{l}\text { Days to } \\
\text { nadir }\end{array}$ & $\begin{array}{l}\text { Relative change } \\
\text { to nadir }\end{array}$ & $\begin{array}{l}\text { Loss }(\mathrm{kg}) \\
\text { to nadir }\end{array}$ & $\begin{array}{l}\text { BCS at } \\
\text { calving }\end{array}$ & $\begin{array}{l}\text { BCS } 40 \\
\text { to } 60 \mathrm{~d}\end{array}$ \\
\hline Calving BW & $0.91(<0.001)$ & $0.42(<0.001)$ & $0.42(<0.001)$ & $0.60(<0.001)$ & $0.35(<0.001)$ & \\
\hline Nadir BW & & $0.32(<0.001)$ & & $0.21(<0.001)$ & $0.35(<0.001)$ & $0.14(<0.001)$ \\
\hline Relative change to nadir & & & & $0.97(<0.001)$ & $0.07(0.004)$ & $0.24(<0.001)$ \\
\hline Loss $(\mathrm{kg})$ to nadir & & & & & $0.15(<0.001)$ & $0.20(<0.001)$ \\
\hline BCS at calving & & & & & & $0.48(<0.001)$ \\
\hline
\end{tabular}




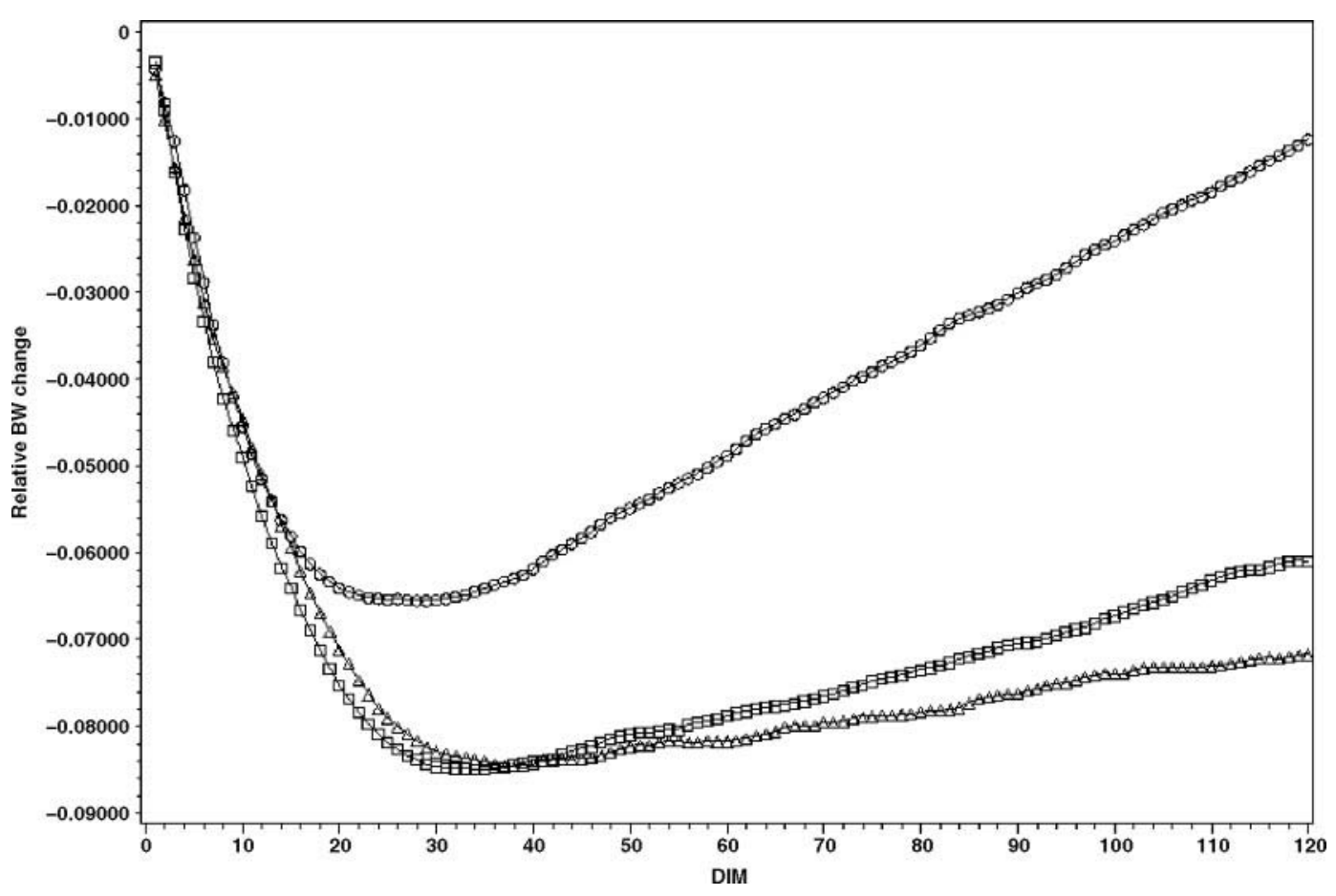

Figure 2. Relative BW change from calving to 120 DIM for first-parity (०), second-parity ( $\square$ ), and older $(\Delta)$ cows, adjusted for farm and repeated BW measurements of the same cow.

3 and above, respectively. From calving to nadir BW, the standard first-parity cow lost $6.5 \%$ of its initial BW. For standard second- and greater-parity cows, relative BW loss was 8.5 and $8.4 \%$, respectively. Gain in BW after nadir was markedly more rapid in first-parity cows compared with older cows. Second-parity cows gained BW at a greater rate than cows of third and greater parity. By 120 DIM, first-parity cows reached $98.8 \%$ of their original BW. Second- and greater-parity cows reached 93.9 and $92.8 \%$ of their original BW, respectively.

\section{Time-Series Analysis}

In total, data from 2,167 cows from 7 farms were available for analysis (Table 5). When time-series analysis was conducted on data from each cow separately, the trend in BW was nonlinear. A 7-d cycle was present in 247 cows (11.4\%) and a 21-d cycle was present in 715 cows $(33.0 \%)$. Incorporating polynomials above the eighth order in the regression did not improve the adjusted $\mathrm{R}^{2}$ substantially, and regression using only polynomials up to the eighth order and harmonic functions for a 7 - and 21-d cycle resulted in an adjusted $\mathrm{R}^{2}$ $\geq 0.5$ in 1,389 cows $(64.1 \%)$. No significant differences were found between cows with adjusted $R^{2} \leq 0.25$ and cows with adjusted $R^{2}$ greater than this value in terms of BW at calving, BCS at calving, and the frequency of metritis, ketosis, and unobserved estrus (data not shown).

Time-series analysis on the complete data set using GEE yielded a nonlinear trend with statistically significant coefficients for polynomials up to the eighth order. Seven-day and 21-d cycles were present as indicated by statistically significant coefficients for the corresponding harmonic functions. The fixed effects of farm and parity were statistically significant. Statistically significant interactions were found between parity and polynomials of the order 1 to 3 (higher order polynomials were not tested). Other significant interactions were found between parity and a 21-d cycle, farm and polynomials of the first 3 orders, farm and a 7-d cycle, and farm and 21-d cycle.

Cows with or without 7- or 21-d cycles in BW did not differ significantly in terms of BW at calving, BCS at calving, the frequency of metritis, ketosis, unobserved estrus, or cumulative 90-d milk production. However, cows without 21-d cycles were more likely to be diagnosed with inactive ovaries than cows with 21-d cycles. Using a logistic regression model (Table 6), the corresponding odds ratio corrected for farm, summer calving, and BCS at calving was 1.51.

Although 7- and 21-d cycles were present in individual time series of daily milk production (90 d), cows in 
Table 5. Time-series analysis of daily BW of individual cows: number of cows (\%) with the corresponding level of adjusted $\mathrm{R}^{2}$ and with or without a significant effect for a 7- or 21-d cycle, obtained from a polynomial regression model with polynomials up to the eighth order and harmonic functions for 7- and 21-d cycles, respectively

\begin{tabular}{|c|c|c|c|c|c|c|c|c|}
\hline \multirow[b]{2}{*}{ Item } & \multicolumn{7}{|c|}{ Number of cows (\%) by farm } & \multirow[b]{2}{*}{ Total (\%) } \\
\hline & DA & HA & LO & MA & NI & YA & YO & \\
\hline \multicolumn{9}{|l|}{ Adjusted $\mathrm{R}^{2}$} \\
\hline $0-0.25$ & 45 (15.7) & $84(34.0)$ & $16(12.2)$ & $51(15.5)$ & $31(15.8)$ & 31 (21.4) & $133(16.0)$ & 391 (18.0) \\
\hline $0.25-0.50$ & 65 (22.7) & 59 (23.9) & $13(9.9)$ & 47 (14.3) & $40(20.4)$ & 26 (17.9) & 137 (16.5) & 387 (17.9) \\
\hline $0.50-0.75$ & 139 (48.4) & $80(32.4)$ & 41 (31.3) & $121(36.8)$ & 77 (39.3) & 39 (26.9) & $283(34.0)$ & $780(36.0)$ \\
\hline $0.75-1.00$ & 38 (13.2) & $24(9.7)$ & $61(46.6)$ & $110(33.4)$ & $48(24.5)$ & 49 (33.8) & $279(33.5)$ & 609 (28.1) \\
\hline Present & $21(7.3)$ & $25(10.1)$ & $22(16.8)$ & $33(10.0)$ & $14(7.1)$ & $22(15.2)$ & $110(13.2)$ & 247 (11.4) \\
\hline \multicolumn{9}{|l|}{ 21-d cycle } \\
\hline Absent & $224(78.0)$ & $185(74.9)$ & $98(74.8)$ & 209 (63.5) & $106(54.0)$ & 92 (63.5) & $538(64.7)$ & $1,452(67.0)$ \\
\hline Present & $63(22.0)$ & $62(25.1)$ & $33(25.2)$ & $120(36.5)$ & $90(46.0)$ & $53(36.5)$ & $294(35.3)$ & 715 (33.0) \\
\hline Total & 287 & 247 & 131 & 329 & 196 & 145 & 832 & 2,167 \\
\hline
\end{tabular}

which these cycles were detected were not necessarily those with the corresponding daily BW cycles. Furthermore, a significant relationship between the presence of a 21 -d cycle in milk production and a 21 -d cycle in BW was not found.

\section{DISCUSSION}

Average BW at calving was greater than that reported by Roche et al. (2007). Mean days from calving to nadir BW increased significantly with parity, indicating that the duration of NEB increased with the increase in parity. Individual variability in DCN within the parity groups was large although some cows (albeit a small fraction) did not reach a nadir in BW within 120 DIM, while others gained BW from calving onward, which most probably contributed to the large standard deviations found. Increase in DCN with parity was not found by Roche et al. (2007) and our values for older cows were much greater. These differences might be partly explained by differences in the study populations, and by the different analytical approach used. Second, we used daily BW measurements, whereas Roche et al.
(2007) used BW measurements spaced at 2-wk intervals.

Mean BW loss from calving to nadir BW increased significantly with parity $(46.5,67.9$, and $77.9 \mathrm{~kg}$ for first, second, and greater parity, respectively). Relative BW change showed this trend. These results suggest that the NEB experienced by first-parity cows is of a smaller magnitude than that experienced by the older cows.

Our findings that $\mathrm{DCN}, \mathrm{LCN}$, and $\mathrm{RCN}$ indicate a smaller energy deficit in early lactation in first-parity cows are in agreement with de Vries et al. (1999), who modeled energy balance in early lactation for different parity groups. Furthermore, our standard relative BW curves (Figure 2) showed that although the initial rate in BW loss seemed similar in the 3 parity groups, first-parity cows lost relatively less BW for less time compared with older cows. Moreover, after nadir in relative BW was reached, first-parity cows regained relative BW faster than older cows, and reached close to $100 \%$ of their BW at calving by 120 DIM.

It must be mentioned that an increase in BW postpartum does not necessarily indicate that a cow is not

Table 6. Farm-adjusted odds ratios with corresponding $95 \%$ confidence intervals (CI) for variables with a significant effect on the probability of being diagnosed with inactive ovaries

\begin{tabular}{lccc}
\hline Variable & Odds ratio & $95 \% \mathrm{CI}$ & $P$-value \\
\hline Summer calving & 1.79 & $1.274-2.508$ & 0.001 \\
$\quad$ No & 1 & - & \\
Yes & 1.51 & $1.105-2.075$ & 0.001 \\
$21-$ d cycle in BW & 1 & - & \\
$\quad$ No & 1.91 & $1.283-2.857$ & 0.008 \\
Yes & 1.02 & $0.578-1.810$ & 0.313 \\
BCS at calving & 1 & - & \\
$\leq 2.5$ & & & \\
$\geq 3.75$ & BCS $<3.75$ & & \\
$2.5<\mathrm{B}$
\end{tabular}


in a state of NEB (Butler and Smith, 1989). This is mainly due to the effect of an increasing gut fill and is demonstrated by Roche et al. (2007), who showed that the nadir in BCS occurred later than the nadir in BW. Nevertheless, as long as a cow is losing BW, it is definitely in a state of NEB. Furthermore, rapid gain in BW, albeit due to a gain in gut fill, could be considered a beneficial property with respect to adaptation to NEB. Under the circumstances of our study, we were not able to determine the effect of gut fill on changes in BW or determine which types of tissues were mobilized during BW loss or gain in early lactation.

Variation in daily BW was largely explainable using polynomials of time and harmonic functions, as indicated by the relative high proportion of cows (64.1\%) with an adjusted $R^{2} \geq 0.5$ in the time-series analysis.

To the best of our knowledge, demonstrating cyclic changes in BW in high-producing dairy cows using harmonic analysis has not been described. Across all farms, $11 \%$ of the cows exhibited a $7-d$ cycle in BW, with a range from approximately 7 to $17 \%$ in the different farms. Seven-day cycles in BW could be related to weekly feeding practices under typical Israeli dairy management. Saturday is the common rest day and fresh TMR is usually not provided on this day. Instead, double amounts are distributed on Friday and are planned to last until Sunday morning. On some farms, some of this TMR undergoes fermentation, which could negatively affect its palatability and nutritious value. If this, in turn, negatively affects DMI, redundant weekly cycles in BW may occur. Under these assumptions, monitoring 7-d cycles could be used as an indirect method for monitoring the soundness of the weekly feeding management. On the other hand, no significant relationships were found between the presence of 7 - $d$ cycles and calving diseases, unobserved estrus, or cumulative 90-d milk production (data not shown).

Twenty-one-day cycles in BW were present in $33 \%$ of the cows (22 to $46 \%$ in the different farms) and are most probably related to the sexual cycle. A 1- to 3-d drop in BW around estrus was observed in cows by Maltz et al. (1997). Cyclic changes in BW by sexual cycle were described in other mammals (Brookhyser and Aulerich, 1980; Fletcher, 1989) and in women (Rosenberg, 1998). These changes could be induced by cyclic hormonal changes influencing metabolism, feed intake, or water retention in body tissues. We found that the presence of these cycles was associated with a reduction of $33 \%$ in the risk of being diagnosed with inactive ovaries. We suggest that the presence of these 21-d cycles in BW is most likely associated with normally functioning ovaries, and monitoring them may be useful for indirectly assessing ovarian functionality at herd level.

\section{CONCLUSIONS}

Days to nadir BW and amount of BW lost to nadir increased with parity indicating that first-parity cows experience a smaller energy deficit in early lactation than older cows. Individual variability in these traits within the parity groups is large, and more research is warranted to establish possible relationships between these measures and milk production and reproductive performance. Based on 255,287 daily BW measurements from 7 dairy farms, loss in relative BW in the standard high-producing Israeli dairy cow continues until d 29, 34, and 38 in lactation, during which time it will lose $6.5,8.5$, and $8.4 \%$ of its $\mathrm{BW}$ at calving for first, second, and greater parity, respectively. Gain in relative BW from nadir onward is markedly more rapid in first-parity cows, and $98.8 \%$ of their BW at calving will be reached by d 120 in lactation. Second-parity and older parity cows regain relative BW at a slower rate and reach 93.9 and $92.8 \%$ of their BW at calving by 120 DIM, respectively.

Daily BW in the first 120 DIM can be modeled using classical time-series techniques. Seven-day and 21-d cycles were present in 11 and $33 \%$ of the cows, respectively. Monitoring the presence of 21-d cycles in daily BW could be useful in indirectly assessing ovarian activity in a herd.

\section{REFERENCES}

Berry, D. P., J. Lee, K. Macdonald, and J. R. Roche. 2007a. Body condition score and body weight effects on dystocia and stillbirths and consequent effects on postcalving performance. J. Dairy Sci. 90:4201-4211.

Berry, D. P., J. M. Lee, K. A. Macdonald, C. R. Staples, K. Stafford, L. Matthews, and J. R. Roche. 2007b. Associations among body condition score, body weight, somatic cell count and clinical mastitis in seasonally calving dairy cattle. J. Dairy Sci. 90:637648.

Bobe, G., J. Young, and D. Beitz. 2004. Invited review: Pathology, etiology, prevention, and treatment of fatty liver in dairy cows. J. Dairy Sci. 87:3105-3124.

Brookhyser, K., and R. Aulerich. 1980. Consumption of food, body weight, perineal colour and levels of progesterone in the serum of cyclic female chinchillas. J. Endocrinol. 87:213-219.

Bruinenberg, M. H., Y. van der Honing, R. E. Agnew, T. Yan, A. M. van Vuuren, and H. Valk. 2002. Energy metabolism of dairy cows fed on grass. Livest. Prod. Sci. 75:117-128.

Buckley, F., K. O’Sullivan, J. Mee, R. Evans, and P. Dillon. 2003. Relationships among milk yield, body condition, cow weight, and reproduction in spring-calved Holstein-Friesians. J. Dairy Sci. 86:2308-2319.

Butler, W. R., and R. D. Smith. 1989. Interrelationships between energy balance and postpartum reproductive function in dairy cattle. J. Dairy Sci. 72:767-783.

de Vries, M. J., S. Van der Beek, L. Kaal-Lansbergen, W. Ouweltjes, and J. Wilmink. 1999. Modeling of energy balance in early lactation and the effect of energy deficits in early lactation on first detected estrus postpartum in dairy cows. J. Dairy Sci. 82:1927-1934. 
de Vries, M. J., and R. F. Veerkamp. 2000. Energy balance of dairy cattle in relation to milk production variables and fertility. J. Dairy Sci. 83:62-69.

Dechow, C., J. Vallimont, and M. O'Connor. 2004. The effect of body weight change on conception. J. Dairy Sci. 87(Suppl. 1):374. (Abstr.)

Diggle, P. 1990. Time Series: A Biostatistical Introduction. Oxford University Press, New York, NY.

Fletcher, T. 1989. Plasma progesterone and body weight in the pregnant and non-pregnant Kowari, Dasyuroides byrnei (Marsupialia: Dasyuridae). Reprod. Fertil. Dev. 1:65-74.

Goff, J. P., and R. L. Horst. 1997. Physiological changes at parturition and their relationship to metabolic disorders. J. Dairy Sci. 80:1260-1268.

Jorritsma, R., T. Wensing, T. A. M. Kruip, P. L. A. M. Vos, and J. P. T. M. Noordhuizen. 2003. Metabolic changes in early lactation and impaired reproductive performance in dairy cows. Vet. Res. 34:11-26.

LeBlanc, S. J., K. Leslie, and T. Duffield. 2005. Metabolic predictors of displaced abomasum in dairy cattle. J. Dairy Sci. 88:159170 .

Maltz, E. 1997. The body weight of the dairy cow: III. Use for on-line management of individual cows. Livest. Prod. Sci. 48:187-200.

Maltz, E., S. Devir, J. Metz, and H. Hogeveen. 1997. The body weight of the dairy cow: I. Introductory study into body weight changes in dairy cows as a management aid. Livest. Prod. Sci. 48:175186.

Marion, E., C. Dechow, J. Appuhamy, and B. Cassell. 2006. The relationship between bodyweight change and disease incidence in early lactation. J. Dairy Sci. 89(Suppl. 1):211. (Abstr.)
Reist, M., D. Erdin, D. von Euw, K. Tschuemperlin, H. Leuenberger Y. Chilliard, H. M. Hammon, C. Morel, C. Philipona, Y. Zbinden, N. Kuenzi, and J. W. Blum. 2002. Estimation of energy balance at the individual and herd level using blood and milk traits in high-yielding dairy cows. J. Dairy Sci. 85:3314-3327.

Reist, M., D. Erdin, D. Von Euw, K. Tschümperlin, H. Leuenberger, H. M. Hammon, N. Künzi, and J. W. Blum. 2003a. Use of threshold serum and milk ketone concentrations to identify risk for ketosis and endometritis in high-yielding dairy cows. Am. J. Vet. Res. 64:188-194.

Reist, M., D. Erdin, D. von Euw, K. Tschümperlin, H. Leuenberger, H. M. Hammon, C. Morel, C. Philipona, Y. Zbinden, N. Künzi, and J. W. Blum. 2003b. Postpartum reproductive function Association with energy, metabolic and endocrine status in high yielding dairy cows. Theriogenology 59:1707-1723.

Roche, J. R., K. Macdonald, C. Burke, J. Lee, and D. Berry. 2007. Associations among body condition score, body weight, and reproductive performance in seasonal-calving dairy cattle. J. Dairy Sci. 90:376-391.

Rosenberg, M. 1998. Weight change with oral contraceptive use and during the menstrual cycle. Contraception 58:345-349.

SAS Institute. 2006. User's Guide Version 9.1: Statistics. SAS Institute, Cary, NC.

Veerkamp, R. F. 1998. Selection for economic efficiency of dairy cattle using information on live weight and feed intake: A review. J. Dairy Sci. 81:1109-1119. 